\title{
A combined variable reluctance network-finite element VR machine modeling for stator inter-turn short-circuit diagnosis
}

\author{
Rabeh Chehda, Noureddine Benouzza, Azeddine Bendiabdellah, Naouel Kada Belghitri \\ Department of Electrical Engineering, University of Science and Technology of Oran MB, Algeria
}

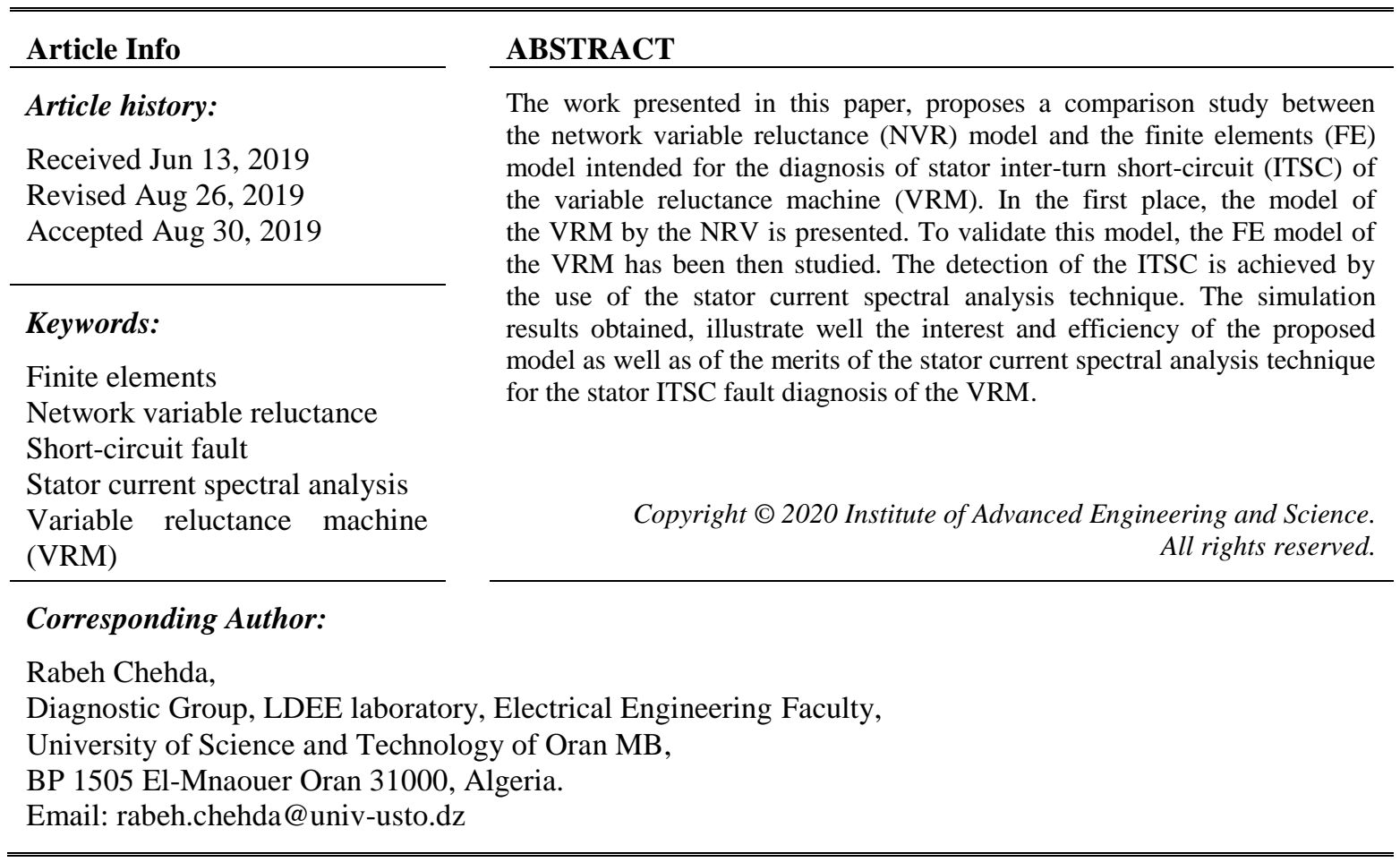

\section{INTRODUCTION}

During the last two decades, power electronics has experienced a great technological development. This allowed restarting work on the variable reluctance machine (VRM). The name of the VRM includes machines of different structures whose common property is the substantial variation in the shape of the gap during rotation.

In general, the performance of the VRM can be comparable to that of synchronous machines with permanent magnets. This machine has many advantages such as robustness, simple construction, low cost, high performance in extreme environments, and ability to operate in degraded mode with a fault in one of its phases [1]. On the other hand, its major drawbacks are the fluctuations of the couple and the acoustic noise that they produce[2].

This machine presents an alternative in a multitude of applications. It occupies an important place especially for applications with variable drives and specific applications such as small tractions, with very satisfactory performance and powers of up to several tens of kilowatts, medical equipment, household appliances, electric vehicles and aerospace field [3, 4].

The VRM is an electromagnetic system involving electrical, magnetic and mechanical quantities. The methods used for the construction of the VRM were formerly empirical; it was necessary to build the machine, to make tests and measurements and to eliminate one by one the various problems and faults encountered. That way is unfortunately expensive and it takes a lot of time to do it. With the development of computing, design and modeling tools, the cost and time of completion have been greatly reduced. Among these modeling methods, one can mention, the analytical methods, solving the Maxwell equations, the seminumerical methods such as the NVR method, the permeance network method [5] and the numerical methods such as the method of FE, boundary elements and finite differences. The choice of the method depends on 
the needs and constraints of the application. The authors [6], presented an FE- boundary element coupled electromagnetic model for calculating parameters such as the flux, the inductance and the static torque of a $8 / 6$ VRM.

Despite its robustness and high reliability, the VRM is subject to several faults that can affect the mechanical, electrical and control parts or possibly combined faults[7,8]. The VRM is exposed to various and varied faults such as: static and dynamic eccentricity [9], short-circuit fault between turns and shortcircuit between phases, bearing faults, etc. These major faults are due to a variety of causes that are associated with design, manufacture or use. A statistical study depicts that the stator and bearing faults account for nearly $80 \%$ of the total faults found in a VRM. For machines with lower power, stator faults are less frequent, while the bearing faults and rotor faults are preponderant for high-speed machines. Figure 1 illustrates the various faults that can occur in a VRM [10].

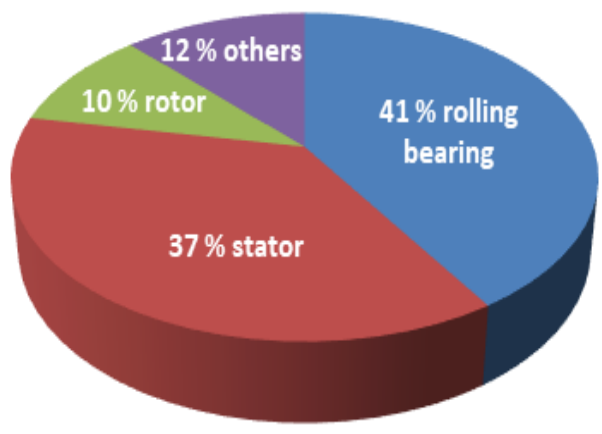

Figure 1. Distribution of faults in a VRM

Several studies have been devoted to the diagnosis of faults in the VRM. The author in [11] presented a new algorithm for the real-time diagnosis of power converter faults in VRM. The presented technique uses only the measured phase currents. In [12], the authors described a 2D FE analysis of a VRM with the static eccentricity. They show the influence of the eccentricity on the static characteristics of the motor and they explain how to obtain the flux lines and the angular position of the rotor according to the healthy and faulty states of the VRM. The research work published in [13], presented a new method of diagnosis of eccentricity in a VRM. The method uses 2D FE analysis to calculate mutual fluxes and induced voltages in an 8/6 VRM. The authors in reference [14] described a study on the effects of the rotor eccentricity on torque in a 4-phase 8/6 VRM.

Different time-frequency methods such as the Wigner-Ville distribution (WVD) and the short-term Fourier transform (STFT) are used in [15] for fault detection. A study presented in [16], consists of studying various electrical faults such as short-circuit and open-circuit in the VRM. The paper in [17] describes the artificial neural network (ANN) combined with the genetic approach (GA) for the detection of faults related to the winding of the stator of the VRM. The same authors developed another diagnostic method, for the detection and classification of stator faults of a VRM [18].

Real-time monitoring of electrical machines is recommended to detect faults and overloads in machines, especially those of electricity generation and those of high power drives. The measured signals containing the significant information due to the fault are usually voltages, currents, speed, vibrations and noise emissions. The development of modern diagnostic methods is increasing due to advances in microelectronics (microprocessor) and signal processing. The technique of spectral analysis of the stator current is the most used because it allows not only the detection of other types of defects but also to overcome accessibility problems [19].

The proposed work presented in this paper, describes the spectral analysis of the stator current applied to the diagnosis of the ITSC fault of the VRM. As a first step, a simulation of the nonlinear model of the VRM based on the reluctance network modeling associated with the method of tooth contours for the calculation of the magnetic field in the gap is presented. A second model based on the FE method has also been developed and proposed. The simulation results of this latter model validate the proposed model based on the NVR method. Next, the focus will be on the study and analysis of the ITSC fault by the spectral analysis of the stator current, using the Fast Fourier Transform (FFT). Finally, the simulation results obtained of the VRM nonlinear model in the healthy state and the faulty ITSC state are presented. 


\section{MODELING OF VRM BY NVR METHOD}

\subsection{The VRM 6/4 geometry studied}

In this paper, our choice is focused on a VRM with six stator teeth and four rotor teeth, because of the simplicity of its geometry and its power supply. The stator consists of the stacked magnetic sheets having six (6) poles around which are arranged the concentric windings. The windings of two diametrically opposed poles are connected in series and form a phase, so we will have three phases for this VRM. The rotor has no active coil or permanent magnet; it also consists of stacked magnetic sheets with four (4) salient poles Figure 1. Two reference positions are determined for each phase. The opposition position $\left(0^{\circ}\right)$ which is the position of misalignment of the axis of the rotor tooth (the tooth Number 1) relative to the axis of the active stator tooth, and the position of conjunction $\left(30^{\circ}\right)$ ) which is the alignment position of the rotor tooth Number 1 with the active stator tooth Figure 2. Successive supply of the stator phases causes a continuous movement of the rotor.

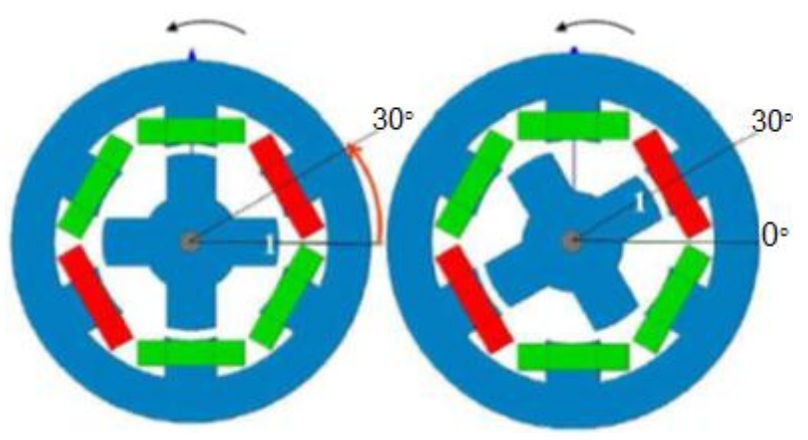

Figure 2. The VRM 6/4 geometry studied

The converter delivers a voltage across each phase having the following equation bellow depending on the position of the rotor; $\mathrm{V}$ The constant voltage delivered by the converter, $\theta_{\text {on }}$ the voltage application duration angle, $\theta_{\text {off }}$ the supply end angle and $\theta_{\text {ext }}$ the angle when the current is equal to zero.

$$
V(\theta)=\left\{\begin{array}{l}
+V \text { si } \theta_{\text {on }} \leq \theta \leq \theta_{\text {off }} \\
-V \text { si } \theta_{\text {off }} \leq \theta \leq \theta_{\text {ext }}
\end{array}\right.
$$

A constant voltage $\mathrm{V}$ is delivered by the converter as a function of the position $\theta$; with: $\theta_{\text {on }}$ the voltage application duration angle, $\theta_{\text {off }}$ the supply end angle and $\theta_{\text {ext }}$ the angle when the current is equal to zero. The inversion of the voltage is necessary in order to reduce or even cancel the braking torque when the next coil attracts the rotor. In order to study the VRM dynamic behavior, the system of (2) has non-linear and interdependent elements.

$$
\begin{aligned}
& U_{1}(\theta)=R \cdot i_{1}(\theta)+\omega \cdot \frac{d \varphi_{1}\left(i_{1}, i_{2}, \theta\right)}{d \theta} \\
& U_{2}(\theta)=R \cdot i_{2}(\theta)+\omega \cdot \frac{d \varphi_{2}\left(i_{2}, i_{3}, \theta\right)}{d \theta} \\
& U_{3}(\theta)=R \cdot i_{3}(\theta)+\omega \cdot \frac{d \varphi_{3}\left(i_{3}, i_{1}, \theta\right)}{d \theta}
\end{aligned}
$$

Where $U_{1}(\theta), U_{2}(\theta)$ and $U_{3}(\theta)$ are the voltages applied to phases $1,2,3$ respectively. $R$ is the resistance of the winding. $\mathrm{i}_{1}, \mathrm{i}_{2}$ and $\mathrm{i}_{3}$ are the phase currents. $\varphi_{1}, \varphi_{2}, \varphi_{3}$ are the main fluxes in the stator poles, $\omega$ is the rotor speed considered constant and $\theta$ is the position of the rotor.

The resolution of such a system requires an elaborate method that will not only determine the electric current, but also the magnetic flux and position. The NVR method is based on the discretization of the domain to be studied in magnetic zones. The flux tubes cross these zones, and the reluctance of the flux tube thus becomes a quantity, which depends on the geometry of the magnetic circuit and its permeability $[20,21]$. The study of the VRM by the NVR makes it possible to represent each zone by a single magnetic reluctance Figure 3. This method is known as the unidirectional reluctance networks method. 


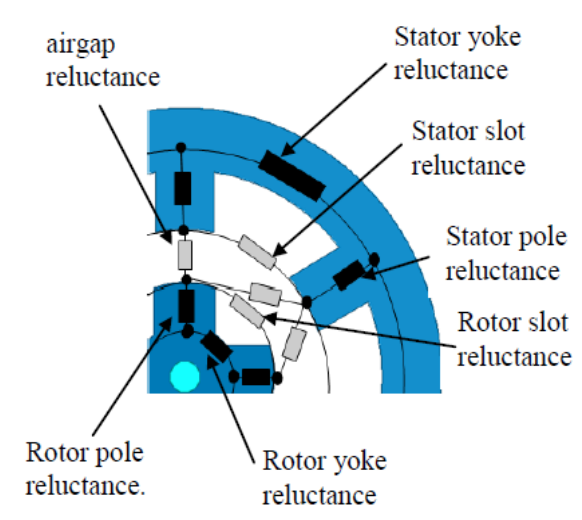

Figure 3. Equivalent reluctances of different magnetic parts of the VRM

The magnetic circuit of the VRM consists of the teeth, the stator and rotor yokes and the stator and rotor slots. For each part having a length $\mathrm{L}$, a height $\mathrm{l}$, and a thickness $\mathrm{h}$, and taking into account the expansion coefficient $\mathrm{k}_{\mathrm{f}}$ due to the laminating of the magnetic sheet, the reluctance can be written as:

$$
\mathcal{R}_{\text {mag }}=\frac{l}{k_{f} \cdot \mu \cdot h \cdot L}
$$

The difficulty of this method is in modeling the air-gap, which takes into consideration the movement. For this, the method of the teeth contours permeances, is then used for its adaptability with the NVR.

\subsection{Formation of the network variable reluctance of the $6 / 4 \mathrm{VRM}$}

The reluctances of all the magnetic parts thus calculated, the network of reluctances of the 6/4 VRM is hence obtained as illustrated Figure 4.

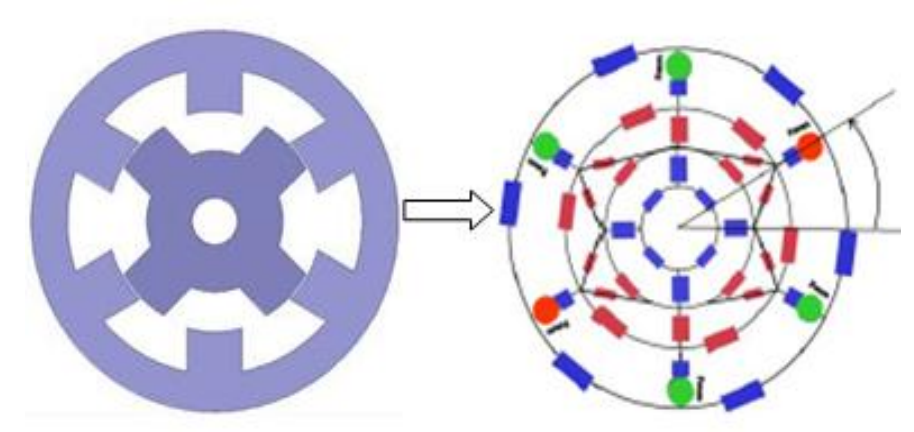

Figure 4. Equivalent reluctance circuit

In our case, we opted for the teeth contour permeances method for the calculation of the reluctances of the airgap for its adaptability to the method of the equivalent reluctance networks. The calculation of these permeances is done according to the following steps:

$$
[F]=[\mathcal{R}] .[\varphi]
$$

Where $[\mathrm{F}]$ is the matrix of magneto-motive force, $[\mathcal{R}]$ is the matrix of the reluctances of the magnetic circuit and $[\varphi]$ is the matrix of fluxes flowing in the meshes. The previous system of (4) is a linear algebraic system. For its resolution, several methods are available among which, the method of Euler. It is a simple method, easy to implement, having a fast convergence and a good precision. The resolution of this system makes it possible to calculate the main flux necessary for the resolution of the differential equation of the VRM and the determination of the current of each phase. In the following, the overall calculation algorithm is depicted by the following Figure 5. 


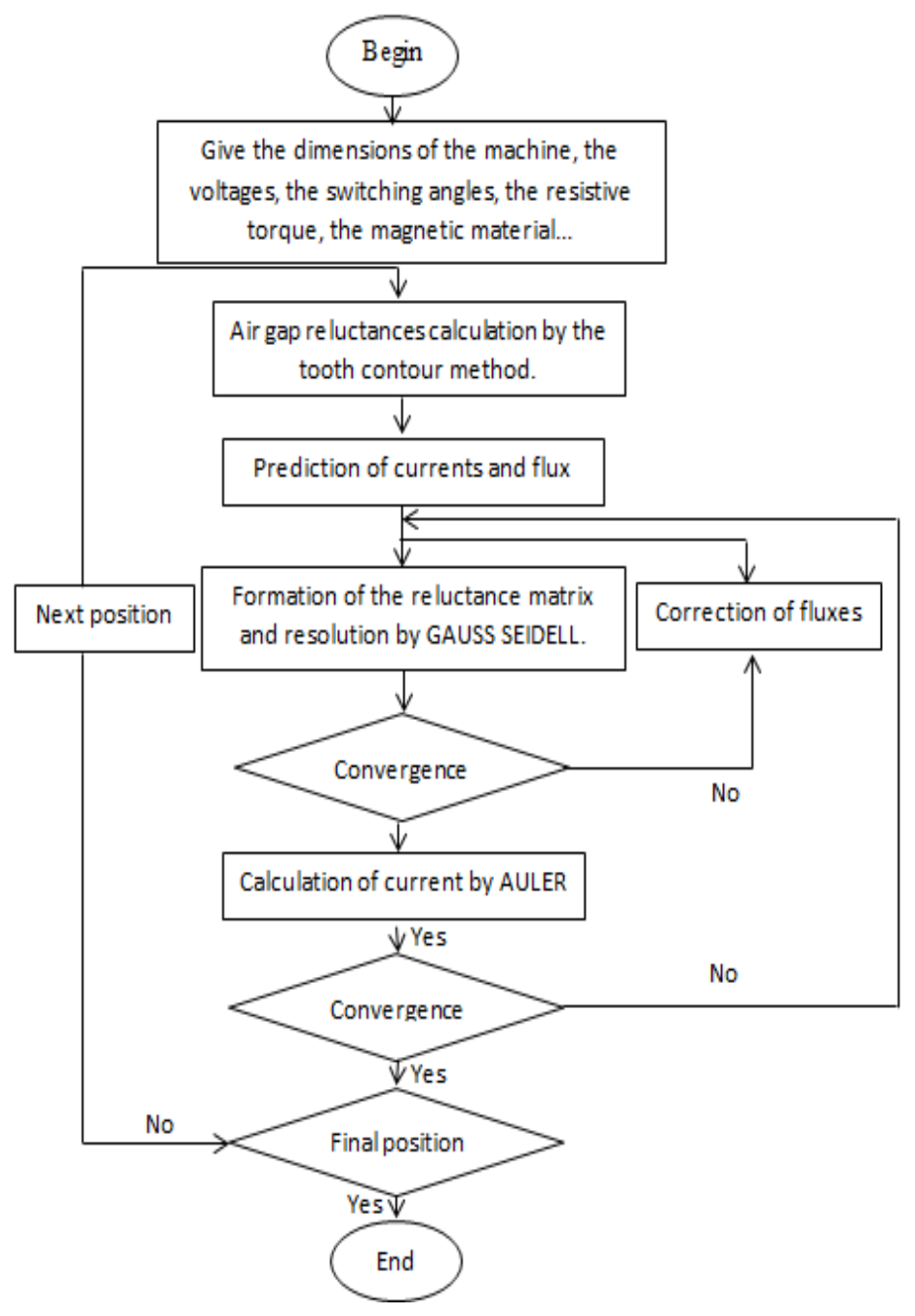

Figure 5. Resolution flowchart of the system of equations representing the VRM

\section{VRM MODELING USING THE FE METHOD}

The FE method in electromagnetism makes it possible to divide the structure of the studied machine into a large number of finite dimensional elements in order to solve the Maxwell equations, with boundary conditions. The combination of all these calculation elements then makes it possible to know the magnetic state of the complete structure and to perform flux, torque, inductance and other physical quantities calculations. The mesh may consist of triangles or quadrilaterals for $2 \mathrm{D}$ domains and tetrahedrons or hexahedrons for 3D domains respectively. Among the advantages that have made the FE method very popular in engineering, one can mention the flexibility that is one of its most important assets. The elements can have many shapes and can therefore easily adapt to any complex geometry. This method also takes into account the inhomogeneous and non-linear properties of the materials. In addition, it takes into account the complexity of the geometry and the variations due to the movement.

The study will be done through computer-aided design (CAD). The tools (that is the software) based on the CAD, can increase the productivity of designers and improve the quality of designs resulting in a reduction of time and cost. Nowadays, there are very good software such as: Ansoft Maxwell, Flux2D or 3D... etc [22], which are all based on the FE method and make it very accessible and applicable to many physical problems. The analysis of the VRM will be done in our case with the Ansoft-Maxwell tool.

Practically, it is enough for a healthy machine to consider a single pole due to the electrical and magnetic symmetry of the machine relative to its axis of rotation, but this is not the case for a faulty machine (with a fault) where symmetry is no longer valid. It is thus necessary to realize the complete geometry of the machine to study its behavior with fault [23]. 


\subsection{VRM analysis by FE method in $2 D$}

The 2D study is done for the magnetodynamic case and in the steady state; however in this case it is necessary to take into account the movement of the rotor. During the movement of the rotor, two reference frames are used; one is linked to the fixed part and the other to the moving part. The mesh of the movable part can be done in three different ways, namely: the remeshing, the mesh deformation and the sliding line. The steady state consists in imposing a constant speed on the rotor (the value of $1500 \mathrm{tr} / \mathrm{min}$ ). The distribution of the flux lines and the distribution of the induction positions $45^{\circ}, 75^{\circ}$ successive are shown Figure 6 and Figure 7. For the supply of the VRM, in the case of the modeling with the FE method, an unbalanced half-bridge inverter is considered, as illustrated by the following Figure 8.

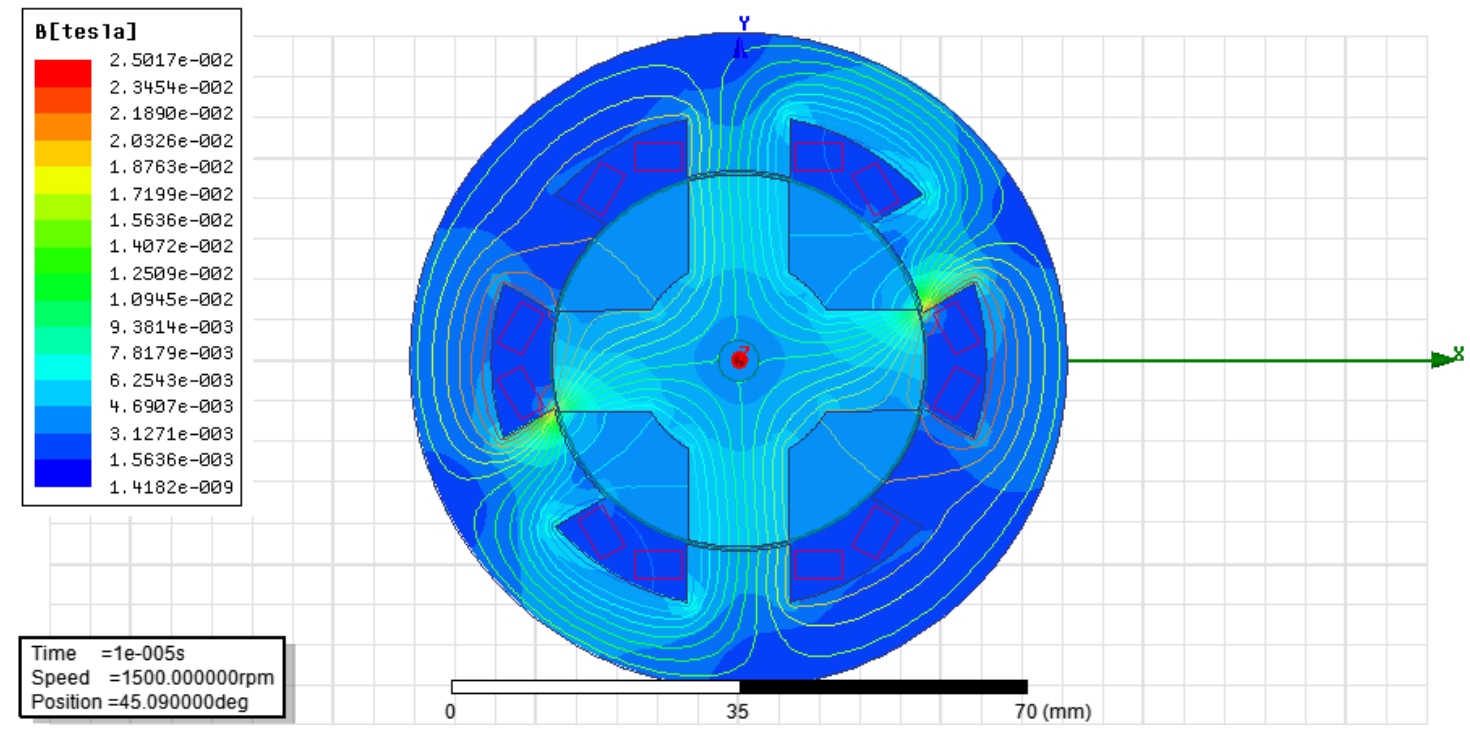

Figure 6. Distribution of flux lines and induction at position $45^{\circ}$

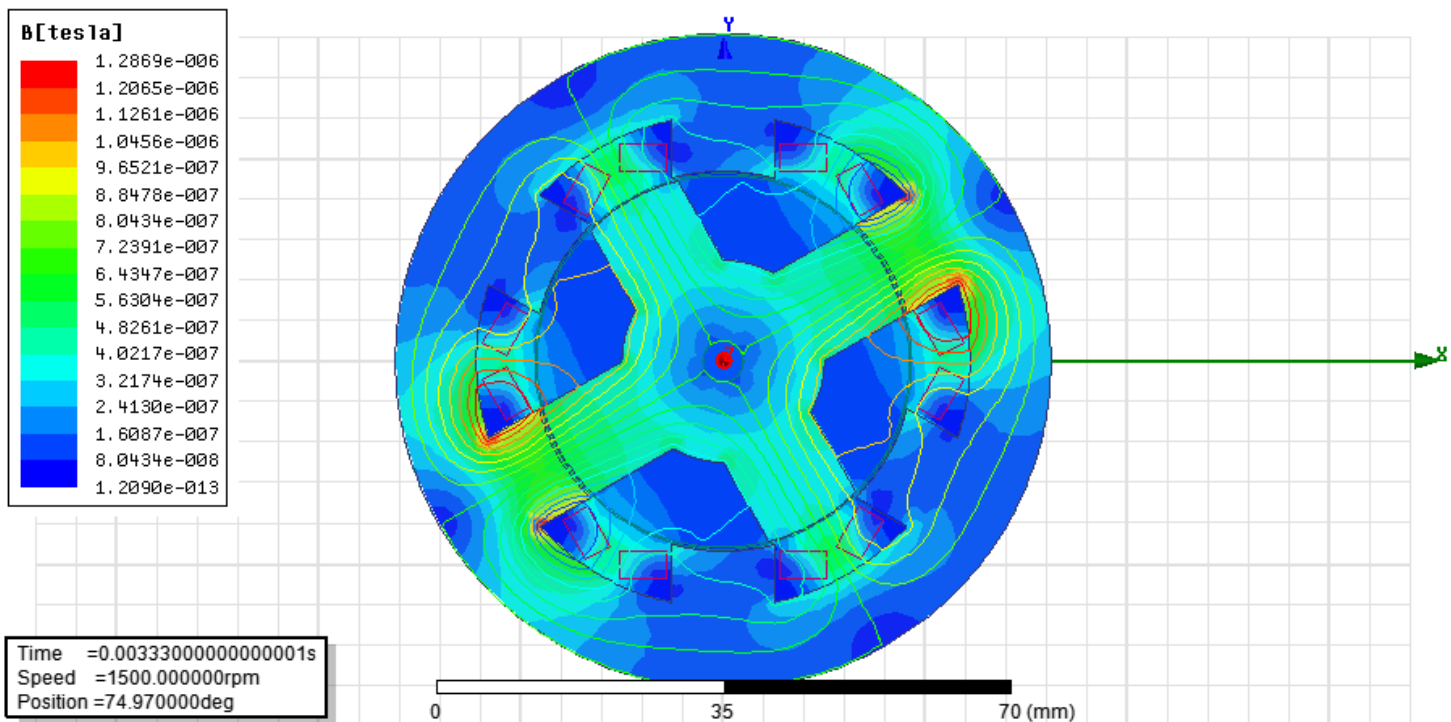

Figure 7. Distribution of flux lines and induction at position $75^{\circ}$ 


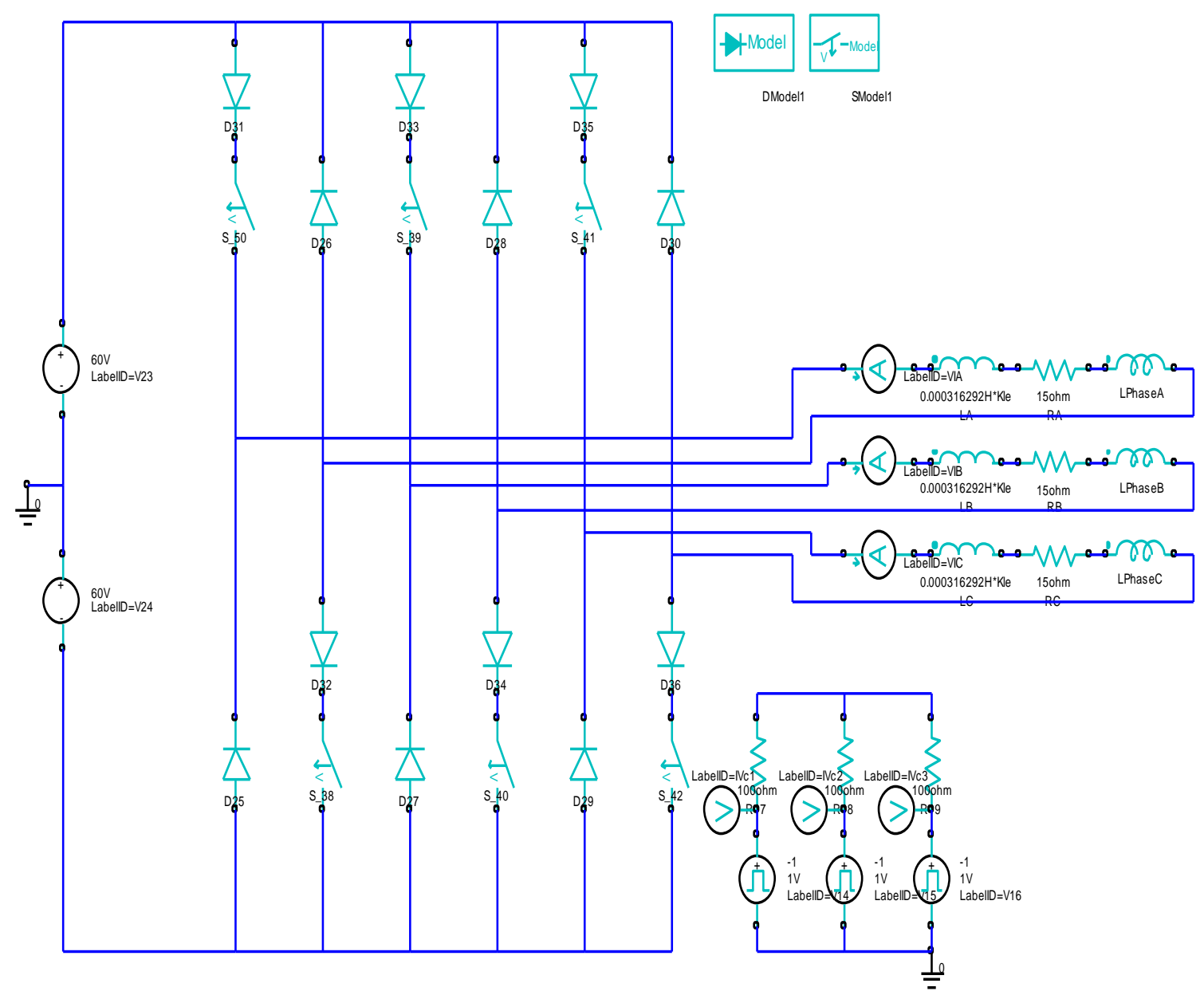

Figure 8. Asymmetric half-bridge inverter

\section{INTEGRATION OF SHORT CIRCUIT FAULT BETWEEN TURNS}

The modeling and simulation of the VRM with ITSC are important steps for the detection of this type of fault and its diagnosis, because it is difficult, even theoretically, to include all the imperfections that exist in the machine in the presence of a fault. In the case of an ITSC fault, one starts with the stator current in the faulty phase because this quantity provides information accessible externally from the machine. A short-circuit between turns of the same phase is a common fault. This fault originates from one or more insulation failures in the winding concerned. It causes a stator current increase in the affected phase.

In a non-linear ITSC fault, the number of turns must be reduced and consequently the stator slot reluctance is reduced. In the healthy state the number of turns $\mathrm{N}$ of the VRM studied is 100 turns. At the instant of the application of a 10\% short-circuit fault, the number of turns reduces to 90 turns in the faulty phase. It is to note that the expressions of the magneto-motive force, the torque and the flux are all given as a function of $\mathrm{N}$.

\section{Use of stator current in detection of the ITSC fault}

The faults that can occur in electrical machines have a direct impact on the frequency content of the stator or rotor currents $[24,25]$. The extraction of the information contained in the discrete signals concerning the fault requires the passage from the time domain towards the frequency domain. The FFT is one of the tools used in the case of stationary signals (steady-state operating electrical machines, faults affecting constant frequency components over time).

The spectral analysis monitoring of the VRM therefore consists in performing a FFT of the quantities affected by the fault, and in displaying the characteristic frequencies constituting the fault signature fault in the VRM. The quantities chosen are electrical (more particularly the stator current). This technique allows a quick and inexpensive monitoring because it requires a simple current sensor placed on or away from the machine. 


\section{SIMULATION RESULTS AND DISCUSSION}

The VRM used in this work has the dimensions mentioned in Table 1. The simulation work is conducted on a VRN model using the Matlab software for numerical simulation, and by the FE method using Ansoft Maxwell software.

Table 1. SRM geometrical caracteristics

\begin{tabular}{ccc}
\hline Dimensions $(\mathrm{mm})$ & Stator & Rotor \\
\hline Inner diameter & 47 & 5 \\
Outer diameter & 81 & 46 \\
Teeth height & 10 & 10 \\
Teeth width & 10 & 16 \\
Yoke thickness & 10 & 9 \\
number x'of poles & 6 & 4 \\
length & 150 & 150 \\
airgap & 0.5 & \\
\hline
\end{tabular}

The results of the simulations presented in this paper, represent the following operating cases:

- Healthy VRM operation (without fault) as a reference case.

- Faulty VRM operation (with ITSC fault).

For each operating case, the simulation of the NVR model and the FE model are performed. The processed quantity used in the simulation work is the stator current. In order to assess the impact of the fault on the stator current signature, a spectral analysis of the current is required. For each operating case, the stator current waveform is therefore shown in both the temporal and the spectral domains. All simulations are performed at the constant imposed speed of $1500 \mathrm{rpm}$ and a voltage of 60 volts. The simulation parameters chosen are respectively; a simulation time of 0.1 second and a sampling frequency of $10 \mathrm{KHz}$. Under these conditions, the resolution frequency is equal to $0.5 \mathrm{~Hz}$.

\subsection{Simulation of the NVR model}

\subsubsection{Operation of the healthy VRM}

The Figure 9(a) and Figure 9(b) respectively, depict the stator current in both temporal and spectral domains in the case of a healthy VRM by using the NVR model. The current increases to a maximum of $8.172 \mathrm{~A}$, then decreases and vanishes and then increases again. The spectrum of the stator current contains the fundamental harmonic $100 \mathrm{~Hz}$ and its multiples.
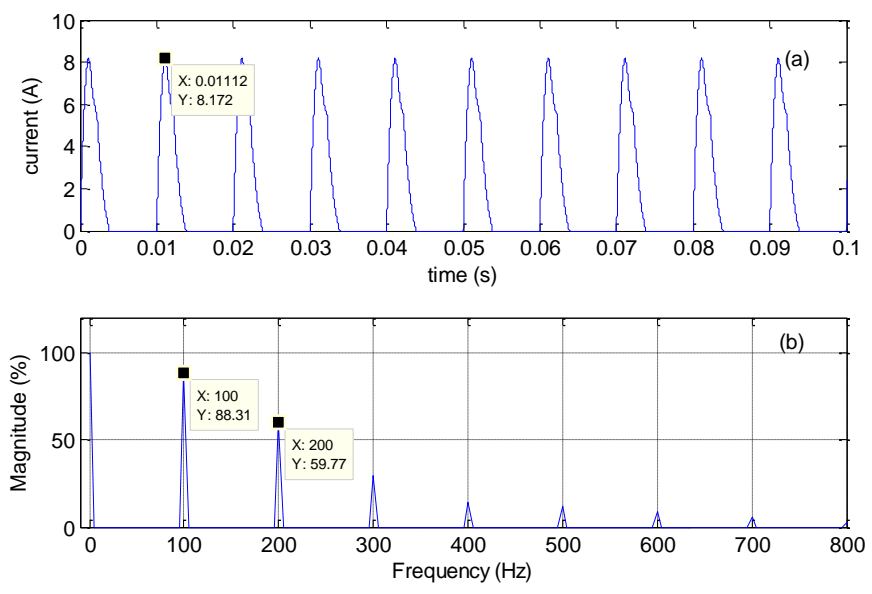

Figure 9. Stator current in the healthy operating case, (a) time domain, (b) spectral domain, (NVR model)

\subsubsection{Machine Operation of the faulty VRM (ITSC fault)}

The ITSC considered in these simulations has a severity of $10 \%$. The Figure 10a and Figure 10b respectively show the stator current in both temporal and spectral domains in the case of a faulty ITSC fault VRM by using the VRN model. In the event of short-circuit of $10 \%$, when comparing the current of the faulty phase with the healthy case, one can observe that the current increases from 8.172 A to $11.63 \mathrm{~A}$. 
It is found that in the case of an ITSC fault, no new harmonics are produced but just an increase in the current amplitude is observed. On the other hand, one can notice a clear increase in the amplitude of the multiple harmonics of the fundamental one. The amplitude variation is larger and visibly clear for the frequencies: $100 \mathrm{~Hz}, 200 \mathrm{~Hz}$ and $300 \mathrm{~Hz}$.
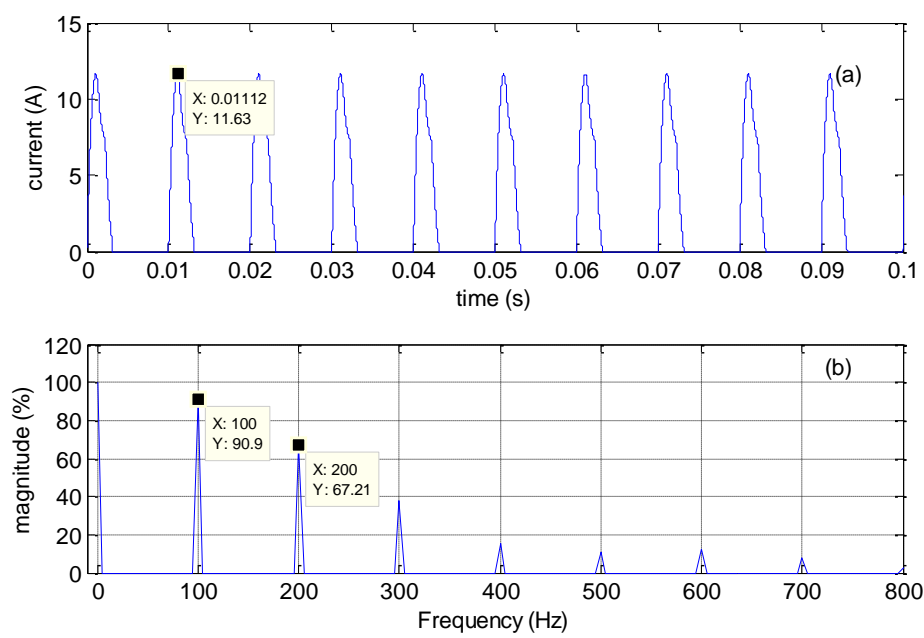

Figure 10. Stator current in the faulty operating case (ITSC fault), (a) time domain, (b) spectral domain, (NVR model)

\subsection{Simulation of the FE model}

\subsubsection{Operation of the healthy VRM}

The Figure 11(a) and Figure 11(b) respectively, show the stator current in both the temporal and spectral domains in the case of a healthy VRM by using the FE model.

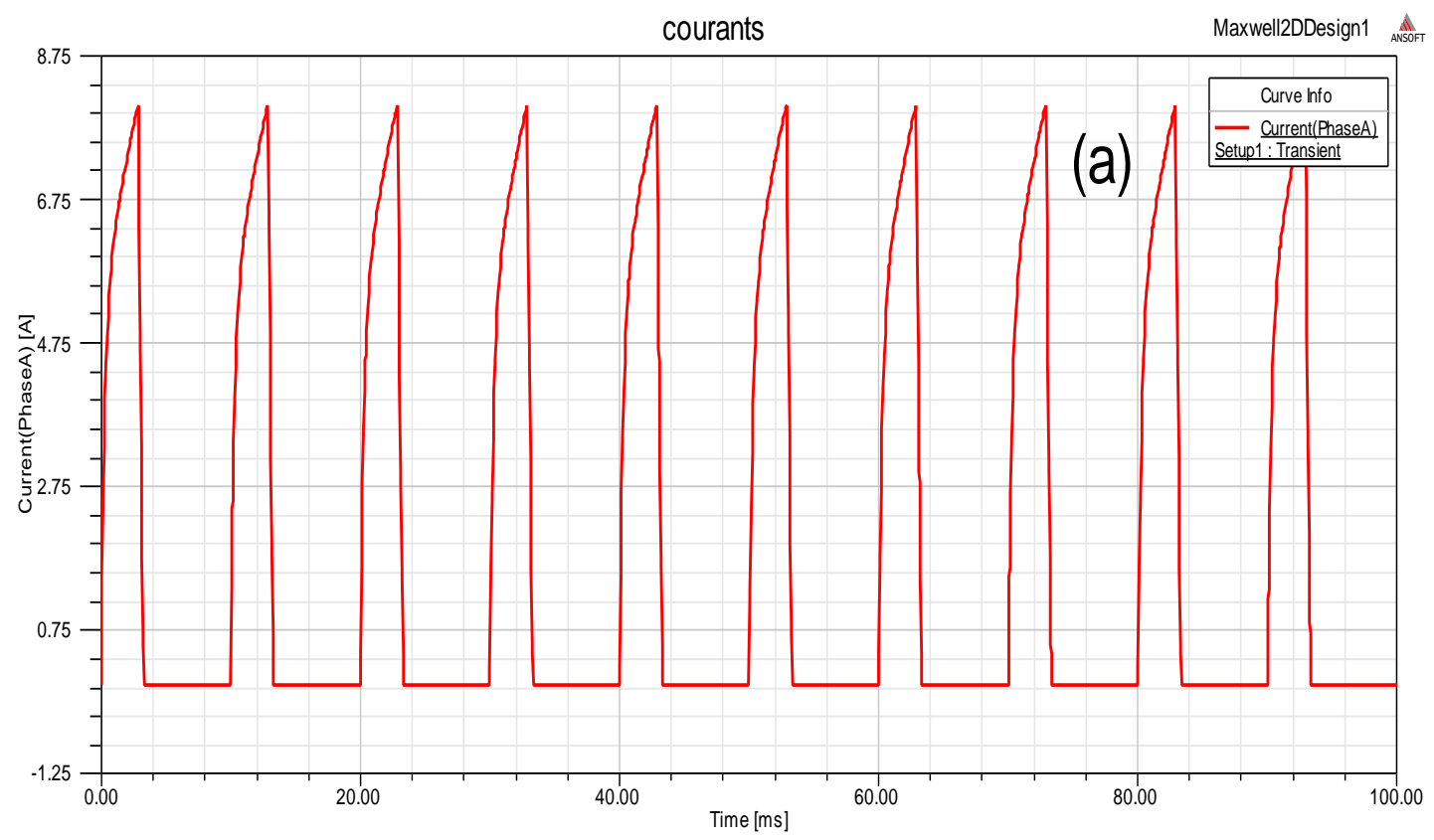

Figure 11 (a). Stator current in the healthy operating case: time domain 


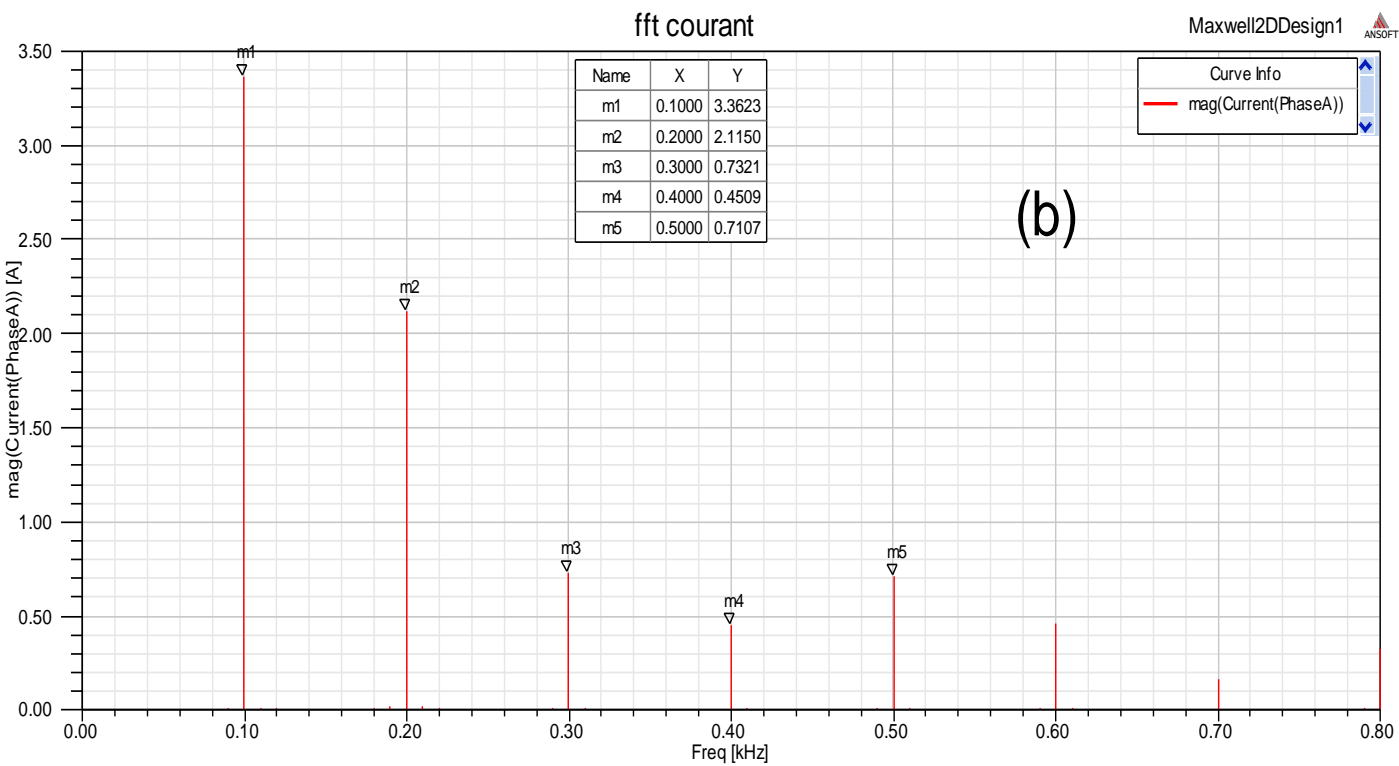

Figure 11(b). Stator current in the healthy operating case: spectral domain, (FE model)

\subsubsection{Machine Operation of the faulty VRM (ITSC fault)}

The Figure 12(a) and Figure 12(b) respectively, show the stator current in both the temporal and spectral domains in the case of a faulty VRM (ITSC fault) by using the FE model. In the same way as the results obtained by the first NVR model, it can be noticed a significant increase in the multiple harmonics of the fundamental.

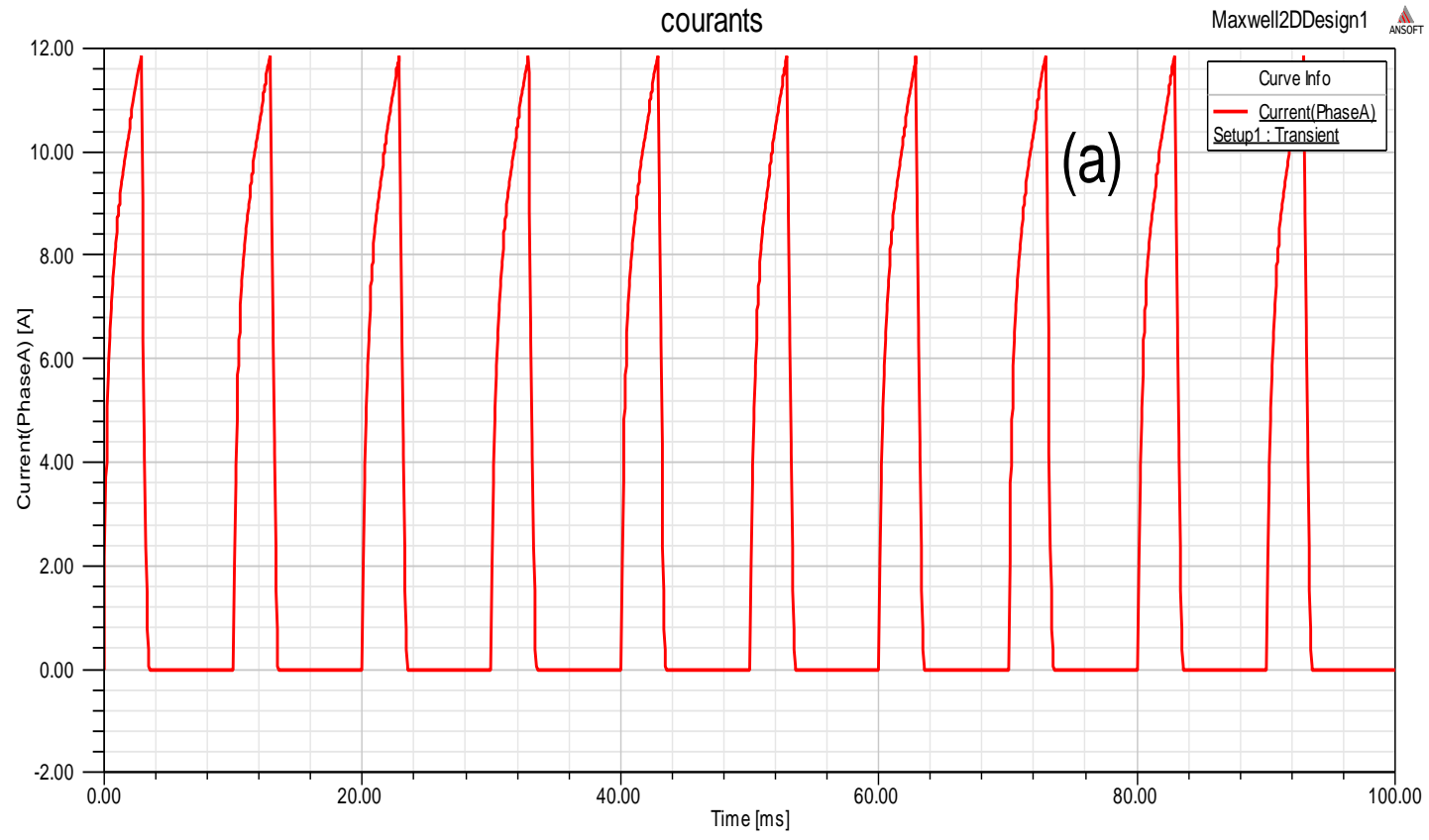

Figure 12(a). Stator current in the faulty operating case (ITSC fault): time domain 


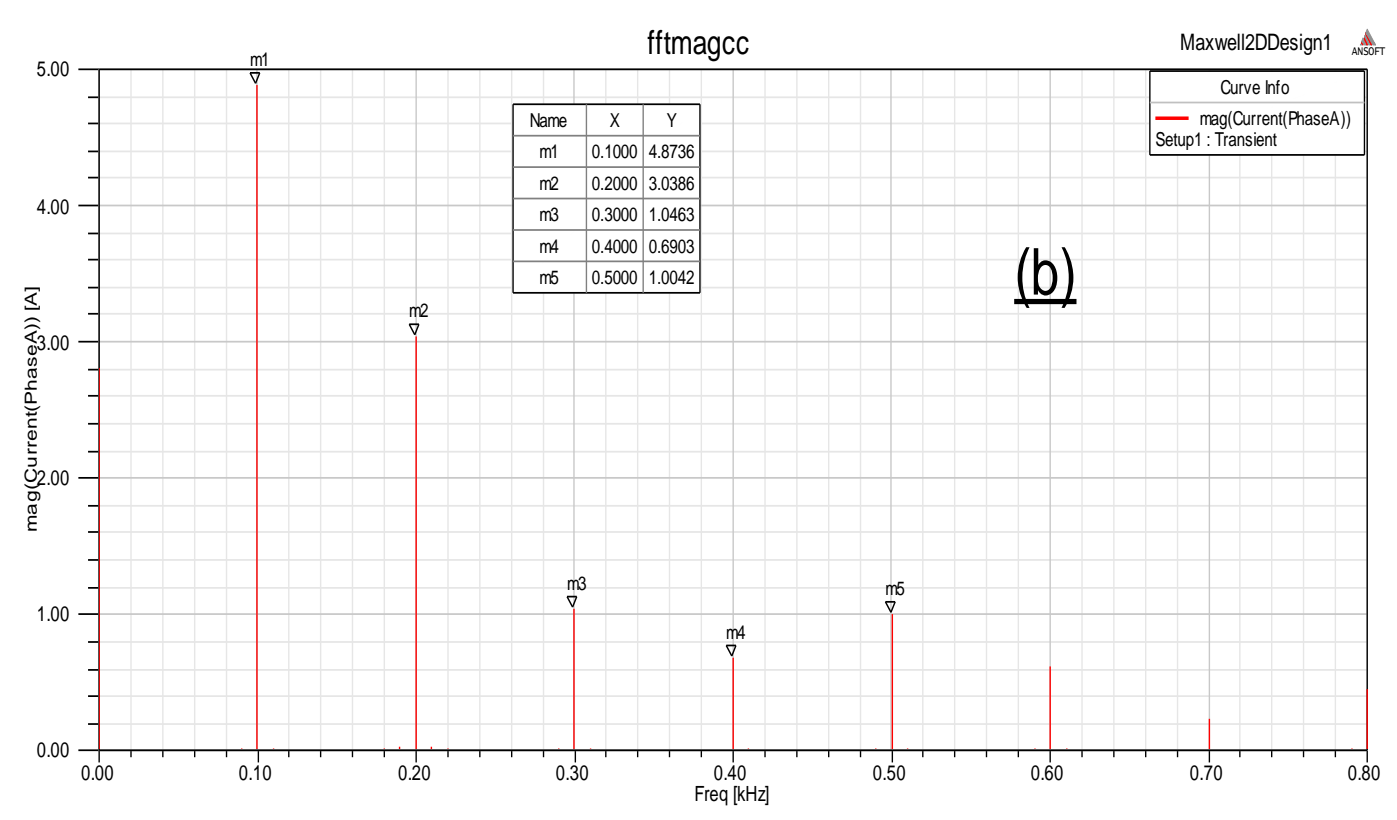

Figure 12(b). Stator current in the faulty operating case (ITSC fault): spectral domain, (FE model)

\section{CONCLUSION}

In this paper, a proposed model of the VRM using the NVR method is first developed and then validated by the FE method. The work is carried out in both the healthy and the faulty (ITSC fault) operating cases in order to verify the proposed models use in the diagnostic field. A stator ITSC fault is incorporated into our models. The diagnosis of the ITSC fault of the VRM is carried out by the use of the spectral analysis of the stator current technique. This technique has shown that the ITSC fault manifests itself by the amplitude increase of the multiple harmonics of the fundamental. The results obtained illustrate the interest and the efficiency of the NVR model when using the stator current technique for the ITSC fault diagnosis.

\section{REFERENCES}

[1] Zhu, Z. Q., Howe, D., "Electrical Machines and Drives for Electric, Hybrid, and Fuel Cell Vehicles," Proceedings of the IEEE, vol. 95(4), pp. 746-765, 2017.

[2] Lin, C., Fahimi, B., "Prediction of acoustic noise in switched reluctance motor drives," IEEE Trans. Energy Convers, vol. 29, (1), pp. 250-258, Mar. 2014.

[3] Sadeghi, S., Mirsalim, M., "Dynamic Modeling and Simulation of a Switched reluctance Motor in a Series Hybrid Electric Vehicle," Acta Polytechnica Hungarica, vol. 7(1), pp. 51-71, 2010.

[4] Mahmoud, I., Rehaoulia, H., Ayadi, M., "Design and modeling of a linear switched reluctance actuator for biomedical applications," International Journal Of Physical Sciences, vol. 6(22), pp. 5171-5180, 2011.

[5] Kada Belghitri, N., Taieb Brahimi, A., Kernane C., "using reluctance network metod in SRM design," In: Proceeding of international conference on electrotechnics ICEL2013, Oran, Algeria, pp. 10-11, 2013.

[6] Becheikh, A.Bendiabdellah and Y.Meslem., "An 8/6 Switched reluctance motor calculation using a combined FE-BE Methods," International Review on Modeling and Simulation, IRMS Review, 2008.

[7] Miremadi, A., Torkman, H., Siadatan, A.," Maximum Current Point Tracking for Stator Winding Short Circuits Diagnosis in Switched Reluctance Motor, "In: IEEE 4th Power Electronics, Drive Systems \& Technologies Conference (PEDSTC), Tehran, Iran, Feb 13-14, 2013.

[8] Saha, N., Panda,S., Choudhury, D.S., Rath, S., Panda S.K., " Comparison on Behavior of Different Faults in Fuzzy Logic and PID Controlled Switched Reluctance Motor Drives," In: IEEE 2nd International Conference on Communication, Control and Intelligent Systems (CCIS), Mathura, India, 18-20 Nov.2016.

[9] Moradi, R., Hajihosseinlui., "A Novel Method for Diagnosis and Analysis of Rotor Faults In Switched Reluctance Motor, " In: IEEE 5th Annual International Power Electronics, Drive Systems and Technologies Conference (PEDSTC), Tehran, Iran, 5-6 Feb. 2014.

[10] Deekshit, K.C., Venu Gopala Rao, M., Srinivasa Rao, R., "DWT based bearing fault detection in induction motor using noisecancellation," Journal of Electrical Systems and Information Technology, vol. 3(3), pp. 411-427, 2016.

[11] Marques, J. F., Estima, J. O., Gameiro, N. S., Cardoso, A. J. M., "A new diagnostic technique for real-time diagnosis of power converter faults in Switched reluctance motor drives," IEEE Transactions on Industry Applications, vol. 50(3), pp. 1854-1860, 2014. 
[12] Faiz, J., Pakdelian, S., "Finite-element analysis of a switched reluctance motor under static eccentricity fault," IEEE Trans. Magn., vol. 42(8), pp. 2004-2008, 2006.

[13] Faiz J., Pakdelian, S., "Diagnosis of static eccentricity in switched reluctance motors based on mutually induced voltages," IEEE Transactions on Magnetics, vol. 44(8), pp. 2029-2034, Aug. 2008.

[14] Dorrell, D. G., Chindurza, I., Cossar, C., "Effects of rotor eccentricity on torque in switched reluctance machines," IEEE Transactions on Magnetics, vol. 41(10), pp. 3961-3963, 2005.

[15] Gopalakrishnan, S., Omekanda, A. M., Lequesne, B., "Classification and remediation of electrical faults in the switched reluctance drive," IEEE Transactions on Industry Applications, vol. 42(2), pp.479-486, 2006.

[16] Bouchareb, I., Bentounsi, A., Lebaroud, A., Batoun, B., "Dynamic Eccentricity Fault Detection In Switched Reluctance Motor Using Time-Frequency Analysis," In: 6th International conference on Sciences of Electronics, Technologies of Information and Telecommunication SETIT 2012, Tunisia, pp. 21-24, 2012.

[17] Bouchareb, I., Bentounsi, A., Lebaroud, A., "An Integrated Artificial Neural Networks/Optimal Time-Frequency Based Classification in Condition Monitoring of Synchronous Reluctance Motor Stator Fault," 9th IEEE International Symposium on Diagnostics for Electrical Machines, Power Electronics \& Drives SDEMPED 2013, Spain, Aug 2013.

[18] Bouchareb, I., Bentounsi, A., Lebaroud, A., "Advanced Diagnosis Strategy for Incipient Stator Faults in Synchronous Reluctance Motor," In: IEEE 10th International Symposium on Diagnostics for Electrical Machines, Power Electronics and Drives (SDEMPED), Guarda, Portugal, pp. 110-116, 2015.

[19] Khodja, M., Aimer, A., Boudinar, A.H., Benouzza, N., Bendiabdellah, A., "Stator Current Model Validation for Rotor Faults Diagnosis," International Journal on Energy Conversion, Vol. 5, (6), November 2017.

[20] Bekkouche, B., Chaouch, A., Mezari,Y., "A Switched Reluctance Motors Analyse using Permeance Network Method," International Journal of Applied Engineering Research, vol. 1(2), pp. 137-152, 2006.

[21] Tang, Y., Motoasca, T.E., Paulides, J. J. H., Lomonova, E.A., "Analytical Modeling of Flux-Switching Machines using Variable Global Reluctance Networks," In: IEEE 20th International Conference on Electrical Machines, france, November 2012.

[22] Benbouzid, M.E.H., "A review of induction motors signature analysis as a medium for faults detection," IEEE Transactions on Industrial Electronics, vol. 47(5), pp. 984-993, 2000.

[23] Zaabi, W., Bensalem, Y., Trabelsi, H., "Analysis of Induction Motor with Stator Winding Short-circuit Fault by Finite Element Model," International Journal of Scientific Research \& Engineering Technology (IJSET), Vol. 3, (3), pp. 53-58, 2015.

[24] Parreira, B., Rafael, S., Pires, A.J., Branco, P.J.C., " Obtaining the magnetic characteristics of an 8/6 switched reluctance machine: from FEM analysis to the experimental tests," IEEE Trans. Ind. Electron, vol. 52, (6), pp. 1635-1643, Dec. 2005.

[25] Elbouchikhi, E., Choqueuse,V., Benbouzid, M., "Induction machine diagnosis using stator current advanced signal processing," International Journal on Energy Conversion, vol. 3(3), pp. 76-87, 2015. 